\title{
Theatre to motivate the study of physics
}

\author{
Marina Carpineti, Michela Cavinato, Marco Giliberti, Nicola Ludwig, \\ Laura Perini
}

\begin{abstract}
A survey we carried out in upper secondary schools showed that the majority of the students consider physics as an important resource, yet as essentially connected to technology in strict terms, and not contributing "culture”, being too difficult a subject. Its appreciation tends to fade as their education progresses through the grades. The search for physics communication methods to increase interest and motivation among students prompted the Department of Physics at the University of Milan to establish the Laboratory of ScienzATeatro (SAT) in 2004. Up to May 2010, SAT staged three shows and one lesson-show having physics as a main theme, for students attending any grades at school. Good indicators of the efficacy of those shows are: the number of repeats (256 of them up to May 2010), the reputation of the theatres in which they were performed, and the results of two surveys on the achievement of the goals, which saw the participation of over 50 classes each.
\end{abstract}

\section{Context}

\section{The Italian situation}

Young people in Italy show a level of basic scientific knowledge which is both disturbing and alarming in many respects. The OECD-PISA (2003-2006) ${ }^{1}$ comparative surveys have found critical gaps in 15year-old Italian students, especially in terms of scientific and mathematical skills which are nowadays considered as key to understanding and acting in our social life and which should be acquired from schooling.

In the $2006^{1}$ OECD-PISA survey, Italy ranked $33^{\text {rd }}$ out of 57 countries in reading skills, $36^{\text {th }}$ in science and $38^{\text {th }}$ in mathematics. Therefore, Italy virtually scores worse than all the countries which have similar lifestyles. In addition, a percentage as high as $25.3 \%$ of Italian students is below the proficiency level, whereas less than $5 \%$ of them find a place in the two top levels of scientific literacy (comparing with an OECD average of $8.8 \%$ ).

However, the mentioned survey concerns skills and not the perception students have of science and scientific operators, whereas the general decrease in students of "hard" science degree courses highlights a decrease in young people's interest in scientific issues.

An Eurobarometer ${ }^{2}$ survey on the causes of European young people's disaffection from scientific studies relates a lack of appeal to the difficulty of these subjects and the poor salary prospects for those working in the world of research.

Nevertheless, a survey on the perception of physics ${ }^{3,4}$ we carried out, with a sample of approximately one thousand high school students in Milan and its province, showed that most of them consider physics as a useful resource. In particular, $80 \%$ of the students (regardless of their age or the school they attend) believe physics is important to society and young people should learn its fundamentals. In a scale from 1 (minimum) to 10 (maximum), the statement "Physics provides an important contribution to society" obtains an average mark of 7.4, whereas the statement "Physics provides an important contribution to the ways of thinking in general" obtains an average mark of 5.8 .

Students perceive physics as a subject mainly related to technological development in strict terms, and what's more they do not see it as closely related to culture, and therefore as incapable to affect the ways society thinks 
and perceives. This is generally considered as a task belonging to humanistic subjects. In addition, about $60 \%$ of interviewees believe physics is too difficult a subject to be understood by most people.

Importantly, it should be added that, according to the data collected, schooling has a negative effect: the appreciation for physics tend to fade over time, generally decreasing as the grade attended increases. Whereas $49 \%$ of the students attending the first two years deem physics fascinating and only $11 \%$ think it is a boring subject, in the fifth year these percentages respectively are $28 \%$ and $21 \%$.,

\section{Science and democracy}

This situation may also have important social repercussions. For example, as Nicoletta Salvatori ${ }^{5}$ says, from a social viewpoint "fully living in democracy today means being scientifically literate", also because "informed people are those who actually have the most critical attitude..." In the book Scienza e media ai tempi della globalizzazione [Science and media in the globalisation era], the authors Pietro Greco and Nico Pitrelli" say that "without a public communication of science there cannot be a real democratic knowledge-based society". Being scientifically literate (which is a lot more than possessing information about science) is nevertheless very complicated. Possessing information alone is not enough to make decisions as required by democracy: in order to do it, a benchmark is needed to interpret data, to distinguish truth from falsity, and one should agree that these categories only make sense if framed by a formal theory. But to make a citizen acquire a formal theory, long and systematic work is needed, and it is in the field of education rather than in the field of popularization.

\section{Science and spirituality}

In our time, many people experience the contrast between spirituality and the dangers created by science as it reveals, discovers, unveils, and rationalizes the world. This contrast dates backs to as remotely as ancient Greece (think of the Myth of Prometheus who is punished by divinities because he gave fire to humans, i.e. scientific and technical knowledge, thus drawing them away from nature and mystery) and has further escalated starting from the mid-twentieth century, "when some of the effects of science and its applications (those of war, in particular) created an image of science that is not always beneficial."7

\section{Goals}

The picture outlined above requires the implementation of teaching approaches which are more effective for learning and especially for enhancing the motivation to study among young people. In 2004, the Department of Physics at the University of Milan established the ScienzATeatro (SAT) Laboratory in order to devise communication methods which could introduce the teaching of physics aiming at enhancing the students' motivation and creating teaching material for initial and lifelong training of teachers. 8

The goals of SAT are the following:

- $\quad$ promoting the dissemination of scientific culture, meeting the urgent demands for information and knowledge from part of our society which spurs us to constant changes and where the role of science and technology becomes more and more crucial;

- meeting a demand, coming from the world of school, for a renewal of teaching methods and scientific subjects, physics in particular;

- developing an activity to highlight the charm of physics, its creative and entertaining aspects, to go beyond the traditional manual-oriented explanation of this subject, proposing it not as something complicated and incomprehensible, only made up of calculations and formulas, but as a lively and interesting experience;

- giving an innovative character to the communication of physics, by avoiding popularisation and devising a training-teaching path to push students towards physics through the use of theatre performances, a means to convey surprise and fascination, as well as an ideal instrument to get citizens (students but also the general public) interested and involved in scientific issues. 


\section{Methods}

\section{From emotions to motivation}

The results of the most recent national and international research projects ${ }^{10}$ stress that the proposals for teaching strategies which are to promote a better learning of physics and its integration into citizens' lifestyles should highlight the model-oriented character of knowledge, allowing the physics-specific viewpoints on the world to gradually emerge. These proposals should compare the complexity of concepts with the complexity of facts. This is not generally done by manuals expressing a "traditional" set-up of knowledge which does not constitute the most effective model for initial learning. What is often necessary to motivate understanding is a profound restructuring of "physics knowledge" itself and a reflection on teaching mediation issues.

Learning and motivation to study should start from the real world students live in and relate to. A student's knowledge, resulting from the interaction with the social and phenomenological reality that surrounds them, is the foundation on which to build a suitable scientific literacy. ${ }^{11,12,13}$ In addition, as the environment a student lives in is so important, it is fundamental to outline an image of physics to be full of charm and potential.

It is therefore evident that a more incisive teaching approach requires a deeper "penetration" of physics into society, with a consequent new and better image of the subject also by developing new professional skills in teachers.

The physics explained at school is often lifeless; it is a systematic and detailed series of answers, without a real understanding of the corresponding questions; it is a science full of fragmented certainties, without any multi-disciplinary link (and often not even infra-disciplinary ${ }^{14}$ ), and most of all emotionless. Luckily enough, what survives in the collective imagery - and in young people in particular - is the scientist's charm and the belief that those working in science are socially important. ${ }^{7}$

So this is our strategy: instead of starting from concepts, hoping to get to the emotions - as schools normally do - let's try to start from emotions, from fascinations, to create the frame of mind to be the basis for the necessary efforts in the study, to make this subject familiar. In short, to generate motivation.

\section{Why theatre}

In the past few years the initiatives aimed at promoting the search of new channels for science communication and at reaching a broad audience with the meaning of culture and of scientific research have multiplied enormously. People have increasingly realised how urgent it is to move on from a communication oriented to the public understanding of science (basically unattainable) to one oriented to the public awareness of science (which now appears to be essential).

A significant growth has been reported in the number of 'popularising' journals, festivals of science films, science centres, science cafés, science festivals, interactive exhibitions, initiatives addressed to children, TV shows (such as the sitcom The Big Bang Theory with an audience of 14 million viewers) and theatre performances.

However, we can see that today the thrill of discovering the unknown often follows non-scientific paths (just think of Harry Potter's success and appeal, the sensation caused by Dan Brown's books or the success of a film such as Avatar and even the popularity of cartoon characters such as the Winx fairies). It is therefore essential to revive contact with truly scientific awe, so that wonder and reason can meet, travel together, favouring a synergic action between science, ethics and society.

Science theatre is the ideal place to promote this kind of meeting and to call forth emotions in a context. As Bertolt Brecht wrote in his essay Brecht on Theatre: "you may still ask with profound concern: won't an evening in such a [scientific] theatre be a most alarming affair? The answer to that is: no. Whatever knowledge is embodied in a piece of poetic writing has to be wholly transmuted into poetry. [...] None the less in an age of great discoveries and inventions [like ours] one is to be sure of enjoying its poetry." 15

A certainty underlies SAT: physics is fascinating and surprising. Physicists do have fun when they study, because understanding and discovering is exciting. 


\section{The strategies by SAT}

When talking about science theatre, we may refer to a large set of experiences which are very different from one another and correspond to different nuances in the science-theatre relation. What is the message to be conveyed? What the audience? What image of science one wants to give? Should - how and to what extent - science and theatre give up something of their own to allow for reasonable and stimulating communication? And lastly, should science theatre addressed to young students rely on concepts or on emotions?

The answers to these questions are closely related to the goals one has set. SAT aims at doing science theatre with the main purpose of generating motivation, as a personal state able to support "virtuous" behaviours and where to lay the foundations to build effective teaching techniques: motivation is indeed one of the relevant aspects missing in young people's approach to physics. In order to succeed in transferring its charm, some choices were essential.

I. Firstly, performances should not turn into lessons, which are to take place in classrooms, not in theatres. In a classroom, students can usually take notes, have a word with their neighbours, ask questions; students find themselves in a well-lit environment and are prepared to learn. On the contrary, in a theatre, the audience is in the dark, sitting in an area visibly separate from the stage, in a silence, and is usually passive. This stillness makes the spectators more willing to embark on the journey told by the performance and prevents them from taking notes, among other things.

II. Secondly, performances should not concern biographies of scientists. In such a case, physics only turns into one of the components of the experience, of the soil where tragedies, love stories and events intertwine and can hardly be the protagonist.

III. Thirdly, popularization should be avoided, although we acknowledge its importance, value and usefulness to our society. This is because well-devised popularization does convey notions, but not the capability to place notions in an individual network of infra- and interdisciplinary relations which promotes the transformation of notions into knowledge, then culture and finally into personal weltanschauung. It simplifies the concepts in everyday language and the change of language tends to distort the meaning of what is to be conveyed. In order to get people engaged in a subject, one has to use the amazing, clear and powerful language of the subject (the physics one not only includes technical terms, but also experiments, pictures, graphs), or else the risk of getting its charm lost is very high. Nobody would really believe that a simplified paraphrase of L'Infinito by Leopardi could elicit emotions. So who could really believe it was possible for electromagnetism or quantum mechanics?

\section{The issue of language}

The issue of the scientific language to be used is very sensitive as theatre communication is very different from both popularization and classroom communication. Therefore, in order to get the spectators' attention, theatre communication has to take them into a world outside by using words, scenery, music and lights.

Physics is complicated and it is its complexity which adds richness and fecundity, leaving room to different points of view, personal views, vital contrasts rooted within culture. In order to convey this complexity, the language to be adopted cannot be everyday language which is non-scientific, non-poetic, hardly accurate... on the contrary "scientific emotions" should be conveyed with as much precision as possible through the true language of art and poetry, and even science. As Claudio Longhi says: "The specificity of theatre is to speak from its 'alternative' and 'non-present' viewpoint. Theatre is distant from anything which is everyday in terms of communication: [therefore] is a medium which speaks [...] to your heart.",16

\section{The issue of actors}

The issue of actors lies in the fact that those who want to convey passion, arouse curiosity, involve and engage the audience in scientific issues should be sensitive to the scientific discourse and language, along 
with the theatre discourse and language. As Salvatore Fruguglietti says: ${ }^{17}$ "The everyday exceptionality of scientific theatre communication should be guaranteed. That's why artists are chosen among those having a scientific interest, those who are willing to explore along with the scientific theme also the scientific method, so that performances (or scientific theatre communication in general) use an artistic language to explain the scientific one."

Over the past few years, the strategy by SAT has been manifold. At the debut, and on particularly relevant occasions, each show was performed by three of the authors (M. Carpineti, M. Giliberti and N. Ludwig) who staged their professional action and therefore interpreted their way to conceive physics and their creativity. To this purpose, they necessarily received training from the directors of the plays to acquire theatrical skills. However, this solution is not always viable, especially when the number of plays exceeds a certain number. In the routine, many repeat performances were staged by professional actors previously trained by SAT physicists on the scientific aspects and at least one physicist was attending the performances for quality control and as an expert for any final debates which may take place. In some cases, the shows were performed by physics university students. This was quite a significant event as it allowed nearly thirty students in four years to have their first approach to science communication techniques, giving them the opportunity to explore some physics subjects.

What's a researcher's role in science communication?

By now it is clear that theatre is an effective communication medium and an extraordinary aid in science communication. However, people are still hardly aware that researchers doing science theatre, or more generally dealing with science communication, are not devoting themselves to a hobby, but are carrying out a truly professional activity, which should be fully acknowledged as part of the research work. "Despite the common beliefs, this type of communication [the public communication of science] cannot be reduced - assuming that somebody ever tried - to a divertissement for retired scientists, failed researchers or casual journalists." 6

\section{Results of the research}

From 2004 to May 2010 three theatre performances and one lesson-show were staged. For a description of the performances, which had an audience (including primary school children, university students and the general public) of approximately 67,000 spectators, out of which 6,000 were teachers, please visit the website http://spettacolo.fisica.unimi.it.

When evaluating the final results of the theatre research activity (as those listed below), one needs to consider the achievement of goals, but also the public's judgment. "And how should we evaluate the public's reaction to the spurs coming from a theatre performance about science? Ears, mouth, eyes! The short moments of silence at the end of a performance before applause bursts, the amazement of those who understood a concept though they believed it was too difficult for them, eyes shining with what Wagensberg called intellectual happiness!",17

'Facciamo luce sulla materia' [Let's Throw Light on Matter]: The Physics Show ${ }^{18}$

Theatre performance for second-cycle primary school students organised by SAT in cooperation with "Teatro del Sole", theatre company for youth-oriented performances. The performance stages a physics laboratory where three scientists carry out 32 experiments on the state of matter and on light and its properties. A publication devoted to teachers was also made available, with sheets containing the details on the experiments. ${ }^{19}$

Duration: 45 minutes + debate of 20 minutes.

Debut: Festival della Scienza in Genoa in 2004.

Total of repeat performances: 230 .

Total audience: 65,000 people.

Table 1 shows the details on a few performances in particularly significant contexts. 


\begin{tabular}{|c|c|}
\hline Year & Performances \\
\hline 2005 & $\begin{array}{l}\text { - Open Day - INFN laboratories in Gran Sasso. } \\
\text { - Congress on Science Dissemination 'Mosaicoscienze' (Mantova and Colline } \\
\text { Moreniche del Garda). } \\
\text { Museum of Natural Science of Brussels - final day of the project LERU Kids } \\
\text { University (three repeats in three languages). } \\
\text { The show was submitted by the Lombardy Regional Authority to a physics contest } \\
\text { for high schools called "Lo spettacolo della fisica: Una classe secondaria adotta } \\
\text { una classe primaria" [The Physics Show: a secondary school class adopts a } \\
\text { primary school class]. The contest saw the participation of about } 600 \text { students from } \\
\text { many schools across Lombardy. }\end{array}$ \\
\hline 2006 & $\begin{array}{l}\text { - Open Day - University of Milan } \\
\text { Open Day - INFN laboratories in Gran Sasso, new version of the show called } \\
\text { "DeLuciDAzioni". } \\
\text { - Science festival Bergamoscienza (Bergamo) - two repeats. }\end{array}$ \\
\hline 2007 & $\begin{array}{l}\text { - Event "Documentaria - Le vie della Scienza le vie dell'educazione" [The ways of } \\
\text { Science the ways of education] (Modena). }\end{array}$ \\
\hline 2008 & $\begin{array}{l}\text { - Science Festival of Novara - two repeats. } \\
\text { Science museum "Phaeno" of Wolfsburg (Germany) invited by the Institute of } \\
\text { Italian Culture - three repeats. }\end{array}$ \\
\hline 2009 & $\begin{array}{l}\text { - Aula magna of the University of Milan within the project Teatro Scienza } \\
\text { (http://www.performingts.it/) - one repeat. } \\
\text { - Piccolo Teatro Studio of Milan - two repeats. }\end{array}$ \\
\hline
\end{tabular}

Table 1. A few performances of Facciamo luce sulla materia in particularly significant contexts.

In order to evaluate the effectiveness of the show with respect to its goals, we: ${ }^{20,21}$

1. interviewed for about 45 minutes a number of children from 57 primary school classes, 26 of whom saw the show in the year of the research, 13 in the previous year and 18 (control group) did not see the show at all;

2. analysed the 188 different questions the children asked at the end of 13 performances;

3. catalogued, according to the experiments staged and their accuracy, 479 drawings randomly chosen among thousands that children spontaneously sent to SAT after the show;

4. analysed the answers to the questionnaires submitted to teachers during 13 performances which concerned the teaching efficacy of the initiative.

The interviews highlighted that children have a lot of articulate memories; they spontaneously emerged in $71 \%$ of pupils in the classes that had seen the show in the year of the research and in $42 \%$ of pupils in the classes that had seen it in the previous year.

Over $80 \%$ of the classes that had participated in Facciamo luce sulla materia gave clear and credible answers to the question "what do physicists study?". Significant examples of answers include: "they do experiments", "they study the colours that are inside white", "they do experiments with liquid nitrogen... that is very cold", "the light... what light can do with water...", which contain an evident reference to the experiments shown in the performance. The same questions had different answers from pupils who had not seen the show, for example: "they study physical education, the body, the organs", "...they study the physical map", "they do experiments on chemicals". In this case the percentage of those giving a correct answer goes down to $20 \%$. And whereas for those who saw the show a scientist who studies the light is "a physicist", some others said it is "an astrologist" or even "a lunar scientist".

The questions asked by pupils at the end of the shows clearly demonstrated how active and enthusiastic their participation was, a sign of their appreciation. They were plentiful, intelligent and interesting and except "were there real scientists or actors on stage?" - all related to physics! As many as $14.5 \%$ of the questions concerned the states of matter, for example "what state do pudding or foam belong to?", "does ice melt in cold or hot water?" The experiments with liquid nitrogen in particular drew the children's attention. Indeed, $20 \%$ of the questions were such as: "when you put a balloon inside that blue container [a dewar flask], why does it go flat?", "what happens if I put my bare hand into nitrogen?", "how come nitrogen does not wet around when you spill it over?" Also infrared camera experiments were really 
successful (approximately 12\% of the questions), as were those with polarisers $(10.5 \%)$. The remaining $43 \%$ of the questions concerned: laser and diffusion, laser and reflection, mirrors, refraction, light-colour and shades, inks, prisms.

Also drawings faithfully depicted the show, with very refined details; they were often accompanied by enthusiastic grateful words. The two most frequently depicted experiments were the one concerning a green laser beam projected onto a transparent tank containing water and Ludox ${ }^{\circledR}$, i.e. silica nanospheres $(22.9 \%)$ and the one with liquid nitrogen $(19.5 \%)$.

Evidently, a few experiments in particular caught the children's attention. Those who were most frequently depicted in a drawing were also those most children's questions were about. Some differences may be ascribable to the difficulty in drawing the subject. For example the properties of Silly Putty ${ }^{\circledR}$, a polymeric viscous-elastic material, are virtually impossible to be depicted in a static context. On the other hand, the experiment with the green laser beam in the tank was depicted also for the scenic character it has during the show.

Finally, also the answers to the questionnaire submitted to the teachers demonstrated a lot of appreciation. As many as $98 \%$ of the teachers believe that the contents of the show had a connection with the course they taught in classes. Out of them, $90 \%$ believe the show was very useful as a teaching aid. In addition, $43 \%$ of the teachers said that basically all the children had spontaneously talked about the show during the first week subsequent to the performance. The children's interest was evaluated as high $(52 \%$ of the teachers), good (46\%), fair (2\%). The understanding of the content was evaluated as high $(19 \%)$, good $(70 \%)$, fair $(11 \%)$. It is important to stress that teachers repeatedly asked for more material and suggestions for further and more detailed work in classrooms.

Luce [Light] ${ }^{22}$

Lesson-show on light for junior secondary schools, staged for "Teatro-Scienza".

Duration: 60 minutes.

Debut: Spazio Eurolab at Piccolo Teatro of Milan in 2008.

Total repeat performances: 10 .

Total audience: 500 people.

A research on the show efficacy has not been carried out yet.

Luce dalle stelle [Light from the stars] ${ }^{23}$

Theatre performance for upper secondary schools; meta-show on astronomic observation at various wave lengths aimed to reflect on the advantages and hazards of scientific popularization.

Duration: 85 minutes.

Debut: Festival della Scienza in Genoa in 2009

Total repeat performances: 7 .

Total audience: 1,200 people.

A research on the show efficacy has not been carried out yet.

Tracce $[\text { Tracks] }]^{24}$

Theatre performance for students of the three-year second cycle at upper secondary schools and universities.

The main theme was: "the eyes cannot see what the mind is not prepared to accept" (taken from the script), articulated through the joy of scientific discovery and a lot of reflections on the meaning and the role of science. ${ }^{25}$

Duration: 55 minutes.

Debut: Teatro Duse in Genoa for the Festival della Scienza in Genoa in 2007.

Total repeat performances: 9 .

Total audience: 2,100 people.

In particular, in 2008 a performance was staged at the Piccolo Teatro Studio of Milan.

For our research on the perception of Physics among the students of upper secondary schools, we analysed approximately one thousand anonymous questionnaires filled in by students before and after seeing the show and questionnaires submitted to teachers. ${ }^{3,4}$

After seeing the show, $22 \%$ of the students developed new ideas concerning physics. They were grouped into categories (Table 2). 


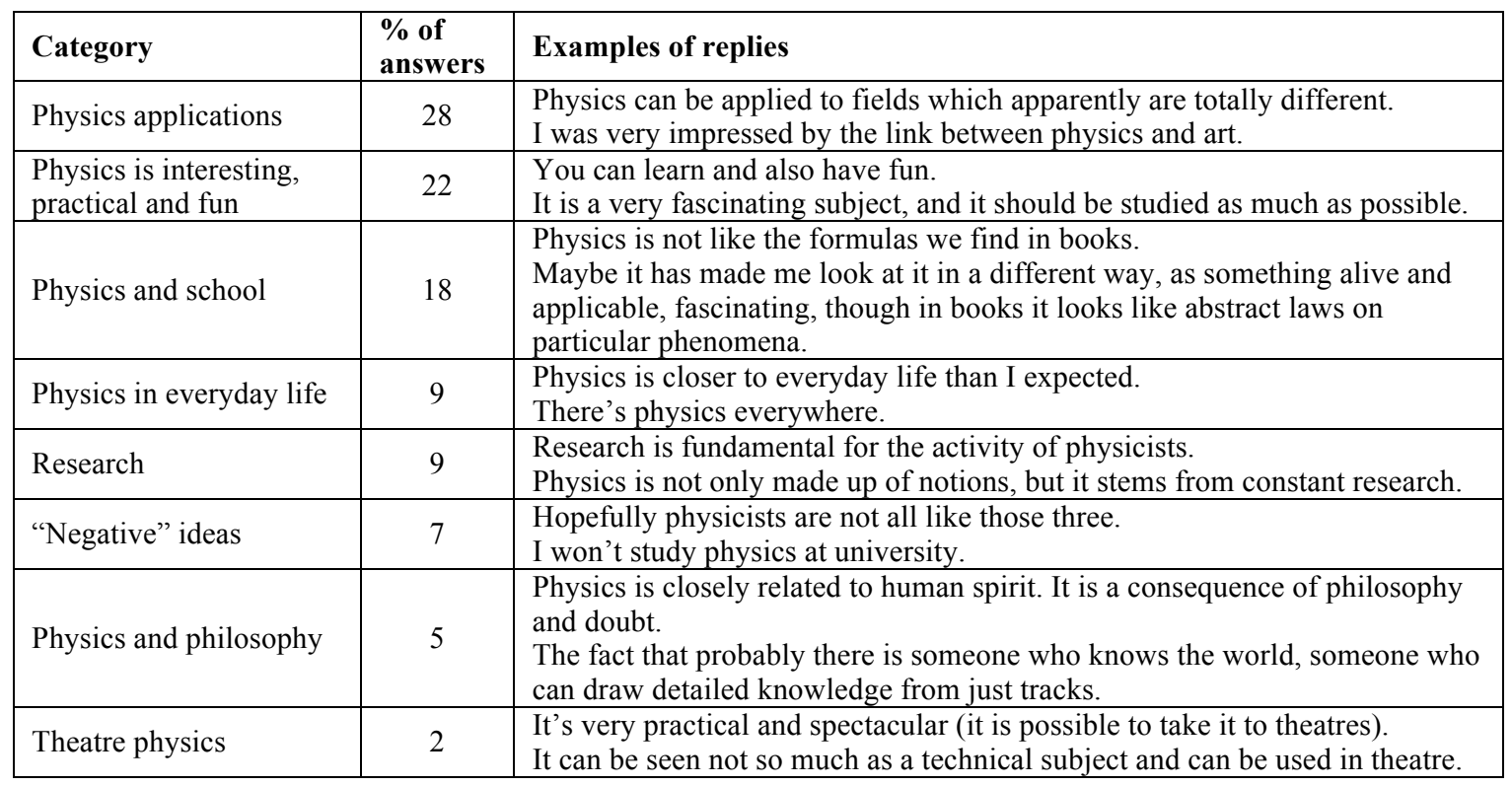

Table 2. Did the show suggest you new ideas with respect to physics?

It should be noted that, out of this $22 \%$ share, $44 \%$ had said they were not interested in physics in the pre-show questionnaire.

A share as high as $41 \%$ of the students said that they would like to further explore the topics dealt with by the show.

Table 3 shows the topics which were selected with their percentages calculated on the number of students.

\begin{tabular}{|l|c|}
\hline \multicolumn{1}{|c|}{ Topic } & \% \\
\hline Optics, reflection, refraction and mirage & 54.3 \\
\hline Infra-red camera & 30 \\
\hline Thermocamera & 9.5 \\
\hline Time-space connection & 6.3 \\
\hline Nuclear physics: microparticles & 6 \\
\hline Astrophysics: supernovae & 5.4 \\
\hline Pendulum oscillations & 4.1 \\
\hline Vector tug-of-war & 3.3 \\
\hline Waves & 2.3 \\
\hline Free fall & 2.3 \\
\hline Research and innovation & 2.3 \\
\hline A physicist's work, experiments & 2.3 \\
\hline The relation between scientific discoveries and ability of the mind to understand them & 2.3 \\
\hline Physics for society & 1.3 \\
\hline The relationship between Physics and Religion & 1.3 \\
\hline The concept of the infinite & 0.9 \\
\hline CERN & 0.8 \\
\hline Science rules out universal reason & 0.4 \\
\hline Escape velocity & 0.4 \\
\hline
\end{tabular}

Table 3. Are there topics you saw in the show you'd like to explore further? If so, specify which ones (maximum three).

It should be noticed that, out of this $41 \%$ share, $76 \%$ had said they were not interested in physics in the pre-show questionnaire. 
Only less than $20 \%$ of the teachers filled in the questionnaire they were asked to answer. The show received an average rating of 8 out of 10 and, with respect to the other initiatives on physics it is above average for $60 \%$ of the teachers, within average for $20 \%$ and below average for $10 \%$. The other $10 \%$ of the teachers said they did not have any benchmarks to compare. According to teachers the appreciation of the show among students received an average evaluation of 6.5 out of 10 .

The majority of the teachers (also those who did not answer the questionnaire) said the show should be accompanied by explanatory material and suggestions for activities in the classrooms and meetings with students.

\section{Conclusions}

In 2004, the Department of Physics at the University of Milan established the SAT Laboratory for research in theatre communication methods for physics which could introduce teaching and aimed at enhancing motivation among students.

The strategy of SAT was to implement a "Physics Theatre", i.e. to write real theatre performances staging scientific experiments accompanied by reflections on the role and the meaning of physics and research work. In order to do this, it was necessary to tackle two very sensitive issues: the language to be used and the choice of the actors. With regard to language, SAT decided to adopt the technical language of physics, with graphs and technical words included in an ensemble of sounds, lights, and evocative and funny gags. With regard to actors, many performances were acted by the authors themselves, others by a theatre company, and others still by students of the faculty of Science. The appreciation of the audience, the reputation of the theatres in which some shows were staged and their numbers are the experimental proofs of the efficacy of the strategy and of the efforts. In addition, two research projects, one on Facciamo luce sulla materia and the other on Tracce, showed that the goals set for primary school were achieved to a significant degree, whereas the goals set for secondary schools were achieved to some extent. Possibly in the latter case results may further improve by handing out teaching materials for teachers and classes.

Finally, the experience gained suggests the use of theatre can be an effective physics communication instrument, also for audiences other than students. Indeed, a small number of performances was opened to the general public, and they saw a remarkable participation by citizens. More and more frequently, SAT has received requests for new repeats like that, and it demonstrates that this innovative approach to physics communication is meeting a larger and larger demand for knowledge coming from citizens.

Translated by Massimo Caregnato

\section{Notes and references}

OCSE, http://www.invalsi.it/download/pdf/pisa06_Primirisultati_PISA2006.pdf

European Commission, Eurobarometer Unit (2001), Europeans, Science and Technology, Eurobarometer, 55.2.

E. Veronesi, La percezione della Fisica negli studenti di scuola superiore: indagine statistica collegata allo spettacolo teatrale Tracce, Thesis for the three-year degree in Mathematics (University of Milan). Supervisor M. Giliberti, Co-supervisor M. Cavinato.

4 M. Giliberti (2010), La Percezione della Fisica negli Studenti di Scuola Secondaria di secondo grado: Indagine Statistica collegata allo Spettacolo Teatrale TRACCE, Frascati Physics Series - Italian Collection, Collana: Scienza Aperta vol. II (2010) - ComunicareFisica2010, Atti 3 Convegno "Comunicare Fisica e altre Scienze", Frascati, 12-16 April 2010.

N. Salvatori, http://www.torinoscienza.it/chi siamo/apri?obj_id=1543.

P. Greco and N. Pitrelli (2009), Scienza e media ai tempi della globalizzazione, Codice Edizione, Torino.

M. C. Brandi, L. Cerbara, M. Misiti and A. Valente (2005), Youth and Science in Italy: between enthusiasm and indifference, JCOM 04(02): A01.

8 M. Cavinato and M. Giliberti (2010), La Fisica in un Laboratorio, di Teatro, Scienzainrete, 16 April 2010 , http://lascienzainrete.it/node/2299.

9 M. Carpineti and N. Ludwig (2010), Fisica e Teatro: una scommessa vinta dal laboratorio SAT, Scienzainrete, 26 April 2010 , http://lascienzainrete.it/node/2427.

10 P. Guidoni (2008), "Presentazione", Approcci e proposte per l'insegnamento-apprendimento della fisica a livello preuniversitario, edited by P. Guidoni and O. Levrini, FORUM Editrice Universitaria Udinese, p. 9-14.

11 A.Tiberghien, E.L. Jossem and J. Barojas (Eds.) (1998), Connecting Research in Physics Education with Teacher Education, I.C.P.E. Book: International Commission on Physics Education.

12 L. Viennot (1996), Raisonner en Physique, DeBoeck.

13 D. Hammer (2000), Student resources for learning introductory physics, American Journal of Physics, Physics Education Research Supplement 68 (S1): S52-S59. 
14 E. Sassi (2009), On the use of new methods and multimedia, general talk MPTL 14, Udine 23-25 September.

B. Brecht, Brecht on Theatre, edited and translated by John Willet. Copyright 1964 by Suhrkamp Verlag, Frankfurt am Main.

6 C. Longhi, http://www.humanitasalute.it/index.php/interviste/salute-e-spettacolo/4019-claudio-longhi-teatro-e-scienza-un-binomio-possibile.

17 S. Fruguglietti (2009), The theatre, (art) and science: between amazement and applause!, JCOM 08(02): C07.

18 By: M. Carpineti, S. Ghioldi, M. Giliberti, N. Ludwig and A. Rota, collaboration between the Department of Physics of the University of Milan and "Teatro del Sole", youth theatre company.

19 M. Carpineti, M. Cavinato, M. Giliberti, N. Ludwig and L. Perini (2009), Guida agli esperimenti di Facciamo Luce sulla Materia: lo Spettacolo della Fisica, Cilea, Consorzio Interuniversitario Lombardo per l'Elaborazione Automatica, ISBN 97888-88971-15-5.

20 M. Carpineti, G. Cavallini, M. Giliberti, N. Ludwig, C. Mazza and L. Perini (2006), Let's throw light on matter: a physics show for primary school, Il Nuovo Cimento 121 B(8): 901-911. ISSN 1594-9982.

21 C. Mazza, Valutazione degli effetti dello Spettacolo della Fisica sulla percezione della scienza nei bambini, Thesis for threeyear degree in physics (University of Milan), Supervisor M. Giliberti, Co-supervisors M. Carpineti, G. Cavallini, N. Ludwig.

22 By: M. Carpineti, M. Giliberti and N. Ludwig.

23 By: M. Carpineti, M. Giliberti, N. Ludwig and S. Sandrelli.

24 By: M. Carpineti, S. Ghioldi, M. Giliberti, N. Ludwig and A. Rota, collaboration between the Department of Physics of the University of Milan and "Teatro del Sole", youth theatre company.

25 R. Kolb (1997), Blind watchers of the sky, Perseus Publishing.

\section{Authors}

Marina Carpineti (Milan, 1965), Department of Physics, University of Milan. She obtained her degree in Physics in 1990 and her Doctor's degree in Physics in 1994. Since 1999 she has been a technical collaborator and presently carries out research in the field of "soft matter" through optical techniques. In addition, she is the author and manager of many dissemination activities and a co-author of four science theatre plays. She has published 25 papers in international journals.

E-mail: marina.carpineti@unimi.it.

Michela Cavinato (Milan, 1955), Department of Physics, University of Milan. Currently a researcher and an adjunct professor of General Physics, she has dealt with Nuclear Physics and in particular with numerical methods and programming techniques for the calculation of electromagnetic reactions and hadron-induced reactions. Thanks to the experience acquired at the SSIS Lombardy - Section of Milan, Cavinato's scientific activity has lately been focused on the research in the Teaching and Communication of Physics. E-mail: michela.cavinato@unimi.it.

Marco Giliberti (Milan, 1962), Department of Physics, University of Milan. Currently he is a researcher and an adjunct professor of Preparation of Teaching Experiences. His research activity has a main focus on the Teaching of Quantum Physics, Training of Teachers and Teaching and Communication of Physics through informal instruments. He is contributing to the "Auger" project for the study and detection of ultra-high-energy cosmic rays. He is the author of over 30 publications and 4 theatre plays.

E-mail: marco.giliberti@unimi.it.

Nicola Ludwig (Milan, 1966), Department of Physics, University of Milan. Currently a researcher, he is an adjunct professor of Analytical Methods for the Study of Cultural Heritage. His research activity concerns diagnostic surveys on monuments (thermography), drawings (infrared reflectography) and on pictorial pigments (fibre optic spectroscopy). Lately, he has been working in Science Communication through theatre and TV shows. He is the author of over 80 scientific papers and a book on Physics techniques applied to cultural heritage. E-mail: nicola.ludwig@unimi.it.

Laura Perini (Milan, 1952), Department of Physics, University of Milan. Full professor of Nuclear and Sub-nuclear Physics. After various experiments of High Energy Physics, since 1992 she has worked in ATLAS at LHC, and in particular on calculation and Grid since 2000. For many years she was the manager of Grid-ATLAS and Calcolo-ATLAS-Italia. She is the vice-director of the Department of Physics and coordinates the Milan centre for LHC calculation. Local manager of the Science Degrees Project, she is the author of over 70 publications in international scientific journals.

E-mail: laura.perini@mi.infn.it.

How to CITE: $\quad$ M. Carpineti, M. Cavinato, M. Giliberti, N. Ludwig and L. Perini, Theatre to motivate the study of physics, Jcom 10(01) (2011) A01. 